\title{
The Geriatric Nutritional Risk Index Predicts Tolerability of Lenvatinib in Patients With Hepatocellular Carcinoma
}

\author{
AKIYOSHI KINOSHITA ${ }^{1}$, NORIKO HAGIWARA ${ }^{1}$, AKIYUKI OSAWA ${ }^{1}$, TAKAFUMI AKASU ${ }^{2}$, \\ YOSHIHIRO MATSUMOTO ${ }^{2}$, KAORU UEDA ${ }^{3}$, CHISATO SAEKI ${ }^{3}$, \\ TSUNEKAZU OIKAWA ${ }^{3}$, KAZUHIKO KOIKE ${ }^{1}$ and MASAYUKI SARUTA ${ }^{3}$ \\ ${ }^{1}$ Division of Gastroenterology and Hepatology, the Jikei University Daisan Hospital, Tokyo, Japan; \\ ${ }^{2}$ Division of Gastroenterology and Hepatology, the Jikei University Kashiwa Hospital, Chiba, Japan; \\ ${ }^{3}$ Division of Gastroenterology and Hepatology, Department of Internal Medicine, \\ Jikei University School of Medicine, Tokyo, Japan
}

\begin{abstract}
Background/Aim: We aimed to investigate the association between The Geriatric Nutritional Risk Index (GNRI) and the tolerability of lenvatinib in patients with hepatocellular carcinoma (HCC). Patients and Methods: We retrospectively evaluated $61 \mathrm{HCC}$ patients treated with lenvatinib and compared those with low GNRI $(\leq 98, n=26)$ to those with high GNRI (>98, n=35). Results: The discontinuation of lenvatinib due to adverse events was more frequent in the low GNRI group (46.2\%) than in the high GNRI group (17.1\%) ( $p=0.014)$. Multivariate analysis revealed that low GNRI ( $p=0.014$ ), hypothyroidism (model 1 $p=0.021$, model $2 p=0.013)$, and advanced age $(p=0.026)$ were independently associated with the discontinuation of lenvatinib. The progression-free survival in the low GNRI group was significantly shorter than that in the high GNRI group (p=0.047). Conclusion: The GNRI might be independently associated with the tolerability of lenvatinib in patients with $\mathrm{HCC}$.
\end{abstract}

Hepatocellular carcinoma (HCC), the most common primary liver cancer, is a major health concern worldwide, and its incidence is rising in Western countries (1). In 2017, there were 953,000 incident cases of liver cancer and 819,000 deaths globally (2), indicating the poor outcomes of this disease despite recent advances in treatment modalities.

This article is freely accessible online.

Correspondence to: Akiyoshi Kinoshita, Division of Gastroenterology and Hepatology, the Jikei University Daisan Hospital, 4-11-1 Izumihon-cho, Komae-shi, Tokyo, 201-8601, Japan. Tel: +81 0334801151, Fax: +81 0334806688, e-mail: aki.kino@jikei.ac.jp

Key Words: Hepatocellular carcinoma, lenvatinib, Geriatric Nutritional Risk Index, tolerability.
Since the REFLECT study showed the non-inferiority of lenvatinib to sorafenib regarding the overall survival of patients with untreated advanced HCC (3), many investigators have reported the efficacy and feasibility of lenvatinib in patients with advanced $\mathrm{HCC}(4,5)$.

However, several investigators showed that an advanced age, poor liver functional reserve, and some adverse events, such as fatigue and appetite loss, were associated with dose reduction or discontinuation of lenvatinib (6-8), leading to a lower dose intensity and reduced objective response of lenvatinib, followed ultimately by a poor survival outcome. Thus, predicting the tolerability of lenvatinib before the initiation of treatment is crucial for achieving favorable survival outcomes in patients with HCC.

The Geriatric Nutritional Risk Index (GNRI) (9), based on the serum albumin level, present body weight, and ideal body weight, was first reported to predict prognosis among elderly patients with acute ill, hemodialysis, and heart failure. Recently, this index was also found to be useful to predict postoperative complications or survival outcomes in cancer patients, including those with $\operatorname{HCC}(10,11)$.

We herein focus on predictive markers for HCC, and report our investigation of the association between the GNRI and the tolerability of lenvatinib in patients with HCC.

\section{Patients and Methods}

Patients. Sixty-one consecutive HCC patients who were treated with lenvatinib from May 2018 to December 2020 at Jikei University Hospital, Jikei University Kashiwa Hospital, and Jikei University Daisan Hospital were enrolled. All medical records were reviewed retrospectively for patients' demographic and clinical data, administration period, dose intensity, objective response, adverse effects (AEs) of lenvatinib, and survival outcomes.

This study was conducted according to the Declaration of Helsinki and the current ethical guidelines and was approved by each institutional ethics board [approval number: 31-023(9522)]. 
Table I. Baseline characteristics of patients.

\begin{tabular}{|c|c|c|c|}
\hline Median (range) & Low GNRI group $(n=26)$ & High GNRI group $(\mathrm{n}=35)$ & $p$-Value \\
\hline Age (years) & $75(47-89)$ & $72(44-89)$ & 0.061 \\
\hline Gender (men/women) & $23 / 3$ & $30 / 5$ & 0.53 \\
\hline ECOG-PS $(0 / 1 / 2)^{\dagger a}$ & $20 / 1 / 2$ & $29 / 4 / 0$ & 0.83 \\
\hline Body weight (kg) & $59.0(43.7-71.3)$ & $65.6(47.8-96.1)$ & 0.003 \\
\hline Body mass index & $22.0(17.3-27.9)$ & $24.1(20.4-32.9)$ & $<0.0001$ \\
\hline Body surface area $\left(\mathrm{m}^{2}\right)$ & $1.6(1.4-1.8)$ & $1.7(1.4-2.1)$ & 0.023 \\
\hline $\operatorname{AST}(\mathrm{IU} / 1)$ & $41(16-140)$ & $34(17-132)$ & 0.34 \\
\hline ALT (IU/1) & $27(9-140)$ & $28(9-149)$ & 0.97 \\
\hline Albumin $(\mathrm{g} / \mathrm{dl})$ & $3.5(2.8-4.0)$ & $4.0(3.1-4.8)$ & $<0.0001$ \\
\hline Total bilirubin (mg/dl) & $0.6(0.2-1.8)$ & $0.7(0.3-6.2)$ & 0.23 \\
\hline Creatinine $(\mathrm{mg} / \mathrm{dl})$ & $0.9(0.6-4.3)$ & $0.8(0.5-1.8)$ & 0.51 \\
\hline $\operatorname{eGFR}\left(\mathrm{ml} / \mathrm{min} . / 1.73 \mathrm{~m}^{2}\right)$ & $68(11-107)$ & $67(29-121)$ & 0.48 \\
\hline Platelet count $\left(10^{4} / \mathrm{mm}^{3}\right)$ & $15.5(9.7-34.6)$ & $14.9(5.5-30.8)$ & 0.41 \\
\hline Prothrombin time $(\%)$ & $92(67-100)$ & $100(26-100)$ & 0.45 \\
\hline Maximum tumor diameter $(\mathrm{mm})$ & $45(12-145)$ & $34(12-148)$ & 0.22 \\
\hline Child-Pugh score $(5 / 6 / 7 / 8)$ & $11 / 10 / 4 / 1$ & $28 / 3 / 4 / 0$ & 0.0059 \\
\hline mALBI grade $(1 / 2 \mathrm{a} / 2 \mathrm{~b} / 3)$ & $2 / 12 / 12 / 0$ & $20 / 11 / 3 / 1$ & $<0.0001$ \\
\hline BCLC stage $(\mathrm{B} / \mathrm{C})$ & $14 / 12$ & $20 / 15$ & 0.8 \\
\hline Portal vein invasion (yes/no) & $7 / 18$ & $7 / 28$ & 0.47 \\
\hline Extrahepatic spread (yes/no) & $4 / 22$ & $10 / 25$ & 0.36 \\
\hline $\operatorname{AFP}(\mathrm{ng} / \mathrm{ml})$ & $4.9(1.6-48,500)$ & $12(1.3-71,100)$ & 0.97 \\
\hline $\mathrm{DCP}(\mathrm{mAU} / \mathrm{ml})$ & $154(10-91,832)$ & $187(17-19,673)$ & 0.77 \\
\hline Initial dose of lenvatinib $(4 \mathrm{mg} / 8 \mathrm{mg} / 12 \mathrm{mg}$ ) & $3 / 19 / 4$ & $4 / 20 / 11$ & 0.34 \\
\hline Initial dose reduction of lenvatinib (yes/no) & $7 / 19$ & $13 / 22$ & 0.4 \\
\hline History of tyrosine kinase inhibitor treatment (yes/no) & $0 / 26$ & $2 / 33$ & 0.33 \\
\hline Comorbidities (absent/present) & $4 / 22$ & $6 / 29$ & 0.57 \\
\hline
\end{tabular}

$\left\lceil\mathrm{a}_{\mathrm{n}}=55\right.$. ECOG-PS: Eastern Cooperative Oncology Group Performance status; AST: aspartate aminotransferase; ALT,:alanine aminotransferase; AFP: $\alpha$-fetoprotein; DCP: des- $\gamma$-carboxy prothrombin; eGFR: estimated glomerular filtration rate; mALBI grade: modified albumin-bilirubin grade; BCLC stage: Barcelona Clinical Liver Cancer stage.

Written informed consent for participation in this study was waived because this study was retrospective and analyzed anonymously.

The diagnosis of HCC and evaluation of the liver functional reserve. The diagnosis of $\mathrm{HCC}$ was confirmed either pathologically or using imaging techniques obtained by four-phase multidetector-row computed tomography (CT) or dynamic contrast-enhanced magnetic resonance imaging (MRI). The diagnosis was made according to the typical hallmarks of HCC (combination of hypervascularity in the late arterial phase and wash out in the portal venous and/or delayed phase) (12).

Tumor-related variables, including the maximum tumor diameter, presence of vascular invasion, presence of extrahepatic metastases, and Barcelona Clinic Liver Cancer (BCLC) classification (12), were evaluated based on these imaging techniques and other variables.

The liver functional reserve was assessed by the Child-Pugh score and modified albumin-bilirubin (mALBI) grade $(13,14)$.

Definition and cut-off value of the GNRI. The GNRI was defined as follows: $1.489 \times$ serum albumin concentrations $(\mathrm{g} / \mathrm{l})+41.7 \times$ pretreatment body weight/ideal body weight $(\mathrm{kg})(9)$. The GNRI is divided into four risk groups: no risk ( $>98)$, low risk ( 92 to 98 ), moderate risk (82 to $<92)$, and major risk (<82) (9). According to a previous study (11), we set the cut-off value at 98: to create a low GNRI group $(\leq 98)$ and a high GNRI group (>98).
Treatment protocol. The initial dose of lenvatinib was determined based on the body weight at inclusion, with a dose of $12 \mathrm{mg} /$ day administered to patients with a body weight $\geq 60 \mathrm{~kg}$ and $8 \mathrm{mg} /$ day to patients with a body weight $<60 \mathrm{~kg}$. At the discretion of the attending physician, the initial dose of lenvatinib was reduced based on the performance status or liver functional reserve.

In case of any Grade $\geq 3$ severe AEs or unacceptable treatmentrelated AEs, the dose of lenvatinib was reduced, or the treatment was discontinued. AEs were assessed according to the National Cancer Institute Common Terminology Criteria for Adverse Events, version 4.0. Based on the guideline provided by the manufacturer, dose reduction or temporary interruption of lenvatinib was maintained until the AEs resolved to Grade 1 or 2 .

The evaluation of the treatment response and follow-up. Patients were followed carefully after the treatment. The treatment response [complete response (CR), partial response (PR), stable disease (SD), or progressive disease (PD)] was evaluated by four-phase multidetector-row CT or dynamic contrast-enhanced MRI four to eight weeks after the initiation of treatment, based on the Modified Response Evaluation Criteria in Solid Tumors (mRECIST) guidelines (15). The relative dose intensity (RDI) was calculated by dividing the actual delivered dose by the standard dose.

The start date of the follow-up was the date of the first administration of lenvatinib. The end date of the follow-up was the 
Table II. Summary of adverse events.

\begin{tabular}{|c|c|c|c|}
\hline Event, n (\%) & $\begin{array}{l}\text { Low GNRI } \\
\text { group }(n=26)\end{array}$ & $\begin{array}{l}\text { High GNRI } \\
\text { group }(n=35)\end{array}$ & $p$-Value \\
\hline \multicolumn{4}{|l|}{ Hypertension } \\
\hline Any grade & $6(23.1 \%)$ & $15(42.9 \%)$ & 0.11 \\
\hline Grade $\geq 3$ & $0(0 \%)$ & $3(8.6 \%)$ & 0.18 \\
\hline \multicolumn{4}{|l|}{$\begin{array}{l}\text { Hand-foot skin } \\
\text { reaction }\end{array}$} \\
\hline Any grade & $7(26.9 \%)$ & $8(22.9 \%)$ & 0.72 \\
\hline Grade $\geq 3$ & $2(7.7 \%)$ & $1(2.9 \%)$ & 0.39 \\
\hline \multicolumn{4}{|l|}{ Fatigue } \\
\hline Any grade & $10(38.5 \%)$ & $12(34.3 \%)$ & 0.74 \\
\hline Grade $\geq 3$ & $2(7.7 \%)$ & $0(0 \%)$ & 0.18 \\
\hline \multicolumn{4}{|l|}{ Appetite loss } \\
\hline Any grade & $7(26.9 \%)$ & $7(20 \%)$ & 0.52 \\
\hline Grade $\geq 3$ & $4(15.4 \%)$ & $2(5.7 \%)$ & 0.21 \\
\hline \multicolumn{4}{|l|}{ Diarrhea } \\
\hline Any grade & $7(26.9 \%)$ & $11(31.4 \%)$ & 0.70 \\
\hline Grade $\geq 3$ & $0(0 \%)$ & $1(2.9 \%)$ & 0.57 \\
\hline \multicolumn{4}{|l|}{ Proteinuria } \\
\hline Any grade & $6(23.1 \%)$ & $9(25.7 \%)$ & 0.81 \\
\hline Grade $\geq 3$ & $4(15.4 \%)$ & $4(11.4 \%)$ & 0.47 \\
\hline \multicolumn{4}{|l|}{ Hypothyroidism } \\
\hline Any grade & $13(50 \%)$ & $19(54.3 \%)$ & 0.74 \\
\hline Grade $\geq 3$ & $0(0 \%)$ & $4(11.4 \%)$ & 0.10 \\
\hline \multicolumn{4}{|l|}{ Others } \\
\hline Any grade & $12(46.2 \%)$ & $11(31.4 \%)$ & 0.24 \\
\hline Grade $\geq 3$ & $5(19.2 \%)$ & $5(14.3 \%)$ & 0.43 \\
\hline $\begin{array}{l}\text { Discontinuation } \\
\text { of Lenvatinib } \\
\text { due to adverse } \\
\text { events }\end{array}$ & $12(46.2 \%)$ & $6(17.1 \%)$ & 0.014 \\
\hline \multirow{8}{*}{$\begin{array}{l}\text { Cause of } \\
\text { discontinuation } \\
\text { (overlapped) }\end{array}$} & Fatigue 3 & Proteinuria 1 & \\
\hline & Appetite loss 3 & Fatigue 1 & \\
\hline & $\begin{array}{l}\text { Tumorlysis } \\
\text { syndrome } 2\end{array}$ & $\begin{array}{l}\text { Appetite } \\
\text { loss } 1\end{array}$ & \\
\hline & Hepatic & Liver & \\
\hline & encephalopathy 2 & damage 1 & \\
\hline & Proteinuria 2 & $\begin{array}{l}\text { Hand-foot skin } \\
\text { reaction } 1\end{array}$ & \\
\hline & Liver damage 1 & $\begin{array}{c}\text { Renal } \\
\text { insufficiency } 1\end{array}$ & \\
\hline & $\begin{array}{c}\text { Hand-foot skin } \\
\text { reaction } 1 \\
\text { Anemia } 1 \\
\text { Renal insufficiency } 1\end{array}$ & $\begin{array}{l}\text { Deterioration } \\
\text { of PS } 1\end{array}$ & \\
\hline
\end{tabular}

PS: Performance status.

time of the last follow-up covered by this study (December 2020) or the time of the patient's death. The progression-free survival (PFS) is defined as the time from the first administration of lenvatinib to disease progression or death from any cause.

Statistical analyses. Comparisons between the groups were carried out using the Mann-Whitney $U$-test for continuous and ordinal variables and the $\chi^{2}$-test or Fisher's exact test for categorical variables. The time to discontinuation of lenvatinib due to AEs and

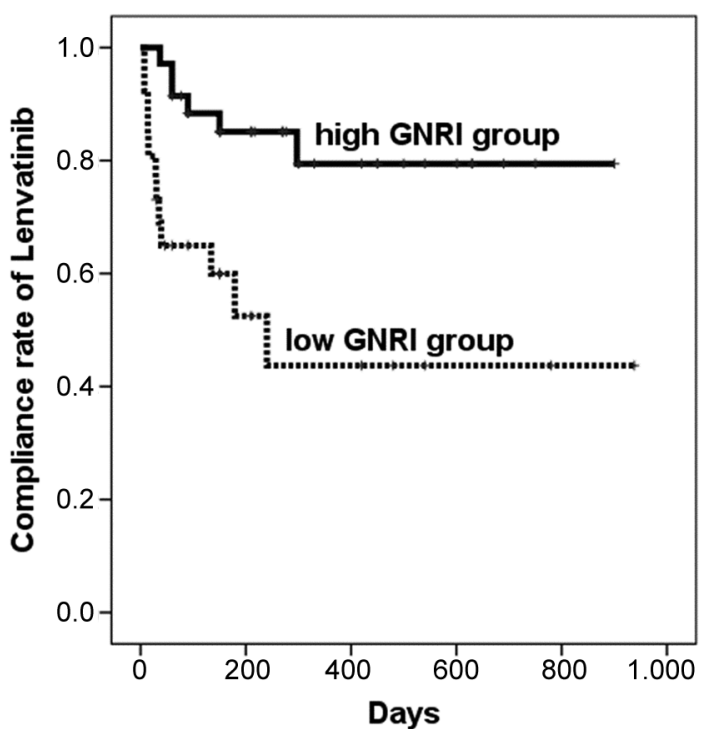

Number at risk

$\begin{array}{rrrrrr}\text { high GNRI group } & 35 & 23 & 11 & 6 & 1 \\ \text { low GNRI group } & 26 & 7 & 5 & 2 & 1\end{array}$

Figure 1. The time to the discontinuation of lenvatinib due to adverse events was significantly shorter in the low Geriatric Nutritional Risk Index (GNRI) group (median 240 days) compared to that in the high GNRI group (not reached during the period) $(p=0.003)$.

the progression-free survival (PFS) were calculated using the Kaplan-Meier method, and differences between the groups were compared by the log-rank test. To evaluate the predictive factors for the discontinuation of lenvatinib, logistic regression analyses were used to calculate the odds ratio (OR) with $95 \%$ confidence intervals (CIs). Both univariate and multivariate analyses for the PFS were performed using the Cox proportional hazard model. The cut-off points of continuous variables for the univariate and multivariate analyses were determined based on the median values. Variables that proved to be significant in the univariate analyses were tested subsequently with a multivariate Cox proportional hazard model. $p<0.05$ was considered statistically significant.

To assess the predictive ability of GNRI and age for the discontinuation of lenvatinib due to AEs or RDI for the objective response ( $\mathrm{CR}$ or $\mathrm{PR})$, receiver-operating characteristic curves (ROCs) were constructed, and the areas under the curves (AUCs) were compared. All statistical analyses were performed using the IBM SPSS Statistics software program, version 19.0 (IBM SPSS, Chicago, IL, USA).

\section{Results}

Baseline characteristics (Table I). A total of 26 patients (GNRI 598 ) were classified into the low GNRI group, and the remaining 35 patients (GNRI >98) were classified into the high GNRI group.

Significant differences were found between the two groups in the body weight, body mass index, body 
Table III. Results of a multivariate analysis for predicting discontinuation of Lenvatinib.

\begin{tabular}{|c|c|c|c|c|c|}
\hline \multirow[b]{2}{*}{ Factors } & \multirow{2}{*}{$\frac{\text { Univariate }}{p \text {-Value }}$} & \multicolumn{2}{|c|}{ Multivariate Model 1} & \multicolumn{2}{|c|}{ Multivariate Model 2} \\
\hline & & Odds ratio $(95 \% \mathrm{CI})$ & $p$-Value & Odds ratio $(95 \% \mathrm{CI}$ ) & $p$-Value \\
\hline Age group ( $\geq 73$ years old) & 0.035 & - & & $4.77(1.21-18.82)$ & 0.026 \\
\hline Gender (female) & 0.60 & - & & - & \\
\hline Creatinine $(\geq 0.84 \mathrm{mg} / \mathrm{dl})$ & 0.48 & - & & - & \\
\hline mALBI grade $(2 a / 2 b / 3)$ & 0.39 & - & & - & \\
\hline Portal vein invasion (yes) & 0.89 & - & & - & \\
\hline Extrahepatic spread (yes) & 0.93 & - & & - & \\
\hline Adverse event: hypertension (yes) & 0.48 & - & & - & \\
\hline Adverse event: hand-foot skin reaction (yes) & 0.71 & - & & - & \\
\hline Adverse event: fatigue (yes) & 0.77 & - & & - & \\
\hline Adverse event: appetite loss (yes) & 0.22 & - & & - & \\
\hline Adverse event: diarrhea (yes) & 0.42 & - & & - & \\
\hline Adverse event: proteinuria (yes) & 0.31 & - & & - & \\
\hline Adverse event: hypothyroidism (yes) & 0.016 & $0.22(0.06-0.79)$ & 0.021 & $0.18(0.046-0.69)$ & 0.013 \\
\hline GNRI ( $\leq 98)$ & 0.017 & $4.82(1.37-16.95)$ & 0.014 & - & \\
\hline Initial dose of lenvatinib (12 mg) & 0.78 & - & & - & \\
\hline
\end{tabular}

CI: Confidence interval; mALBI grade: modified albumin-bilirubin grade; GNRI: Geriatric Nutritional Risk Index. Significant $p$-Values are shown in bold.

surface area, serum albumin, Child-Pugh score, and mALBI grade.

AEs and the tolerability of lenvatinib. A total of $95.1 \%$ (58/61) developed treatment-related AEs. There were no fatal treatment-related AEs. The most common AEs were hypothyroidism $(52.5 \%)$, followed by fatigue $(36.1 \%)$, hypertension $(34.4 \%)$, diarrhea $(29.5 \%)$, hand-foot skin reaction $(24.6 \%)$, proteinuria $(24.6 \%)$, and appetite loss $(22.3 \%)$.

The frequency of AEs (both any grade and Grade $\geq 3$ ) was not significantly different between the two groups. However, the discontinuation of lenvatinib due to AEs was more frequent in the low GNRI group $(12 / 26,46.2 \%)$ than in the high GNRI group $(6 / 35,17.1 \%)(p=0.014)$ (Table II).

The time to discontinuation of lenvatinib due to AEs was also significantly shorter in the low GNRI group (240 days) compared to the high GNRI group (not reached during the period) ( $p=0.003$ ) (Figure 1).

Given the correlations between the GNRI and mALBI grade (both include albumin), we constructed two multivariate models: model 1 included the variables of age, sex, creatinine, portal vein invasion, extrahepatic spread, each adverse event, GNRI, and initial dose of lenvatinib. Model 2 included the variables of age, sex, creatinine, mALBI grade, portal vein invasion, extrahepatic spread, each adverse event, and initial dose of lenvatinib. A multivariate logistic regression analysis revealed that a low GNRI $(\mathrm{OR}=4.82 ; 95 \% \mathrm{CI}=1.37-16.95, p=0.014)$, hypothyroidism (model $1 \mathrm{OR}=0.22 ; 95 \% \mathrm{CI}=0.06-0.79, p=0.021$, model 2 $\mathrm{OR}=0.18 ; 95 \% \mathrm{CI}=0.046-0.69, p=0.013)$, and advanced age
$(\mathrm{OR}=4.77 ; 95 \% \mathrm{CI}=1.21-18.82, p=0.026)$ were independently associated with the discontinuation of lenvatinib (Table III).

The GNRI $(0.671, p=0.037)$ and hypothyroidism $(0.675$, $p=0.032$ ) had higher AUC values for the discontinuation of lenvatinib due to AEs compared to the advanced age $(0.652$, $p=0.063$ ).

Therapeutic response to lenvatinib and the association with $R D I$. The objective response rate (ORR) and disease control rate (DCR) were $34.6 \%(9 / 26)$ and $57.7 \%(15 / 26)$, respectively, in the low GNRI group and $51.4 \%(18 / 35)$ and $94.3 \%(33 / 35)$, respectively, in the high GNRI group $(p=0.19 ; 0.0021)$.

The ROC curves of the 4-, 8-, and 12-week RDI were constructed for the objective response (CR or PR), and the AUCs were then compared. The 8-week RDI (0.679) had a higher AUC value than the 4-week RDI $(0.565)$ or 12 -week RDI (0.586).

Patients with CR or PR had a significantly higher 8-week RDI $(78.6 \%)$ than those with SD or PD (50.9\%) $(p=0.02)$. Patients with mALBI 1 had a significantly higher 8-week RDI $(92.9 \%)$ than those with mALBI $2 \mathrm{a}$ or $2 \mathrm{~b}(62.5 \%)$ $(p=0.003)$. Patients in the low GNRI group had a significantly lower 8 -week RDI $(56.7 \%)$ than those in the high GNRI group (75\%) $(p=0.019)$.

The PFS and prognostic factors. The cumulative PFS at 50, 100,150 , and 200 days was $82.8 \%, 65.3 \%, 43.6 \%$, and $38.7 \%$ in the low GNRI group, respectively, and $97.1 \%$, $91.3 \%, 84.7 \%$, and $81.3 \%$ in the high GNRI group, respectively. The PFS in the low GNRI group was 


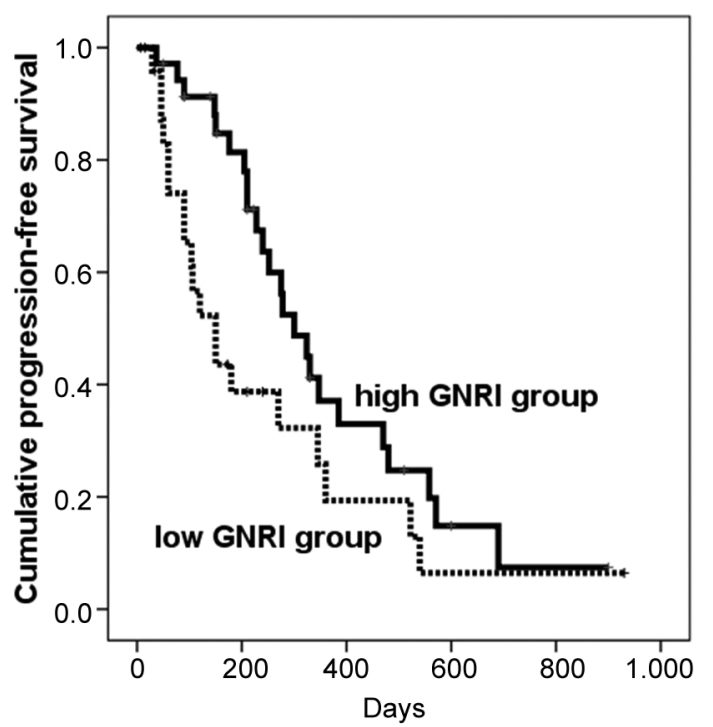

$\begin{array}{rrrrrr}\text { Number at risk } & & & & & \\ \text { high GNRI group } & 35 & 24 & 8 & 3 & 1 \\ \text { low GNRI group } & 26 & 8 & 3 & 1 & 1\end{array}$

Figure 2. Progression-free survival in the low Geriatric Nutritional Risk Index (GNRI) group was shorter than that in the high GNRI group (hazard ratio $=1.83,95 \% C I=0.996-3.351, p=0.047$ ).

significantly shorter than that in the high GNRI group [hazard ratio $(\mathrm{HR})=1.83,95 \% \mathrm{CI}=0.99-3.35, p=0.047$ ) (Figure 2).

Given the correlations between the GNRI and mALBI grade (both include albumin), we constructed two multivariate models: model 1 included the variables of age, sex, creatinine, BCLC stage, portal vein invasion, extrahepatic spread, AFP, objective response, GNRI, initial dose of lenvatinib, and 8-week RDI. Model 2 included the variables of age, sex, creatinine, mALBI grade, BCLC stage, portal vein invasion, extrahepatic spread, AFP, objective response, initial dose of lenvatinib, and 8-week RDI. The results of the univariate and multivariate analyses are shown in Table IV. The multivariate analysis revealed that objective response $\quad(\mathrm{HR}=0.39 ; 95 \% \mathrm{CI}=0.17-0.88, p=0.023)$ was independently associated with PFS.

\section{Discussion}

In the present study, the discontinuation of lenvatinib due to AEs was more frequent in the low GNRI group than in the high GNRI group. The time to discontinuation of lenvatinib due to AEs was also significantly shorter in the low GNRI group than in the high GNRI group. Multivariate analyses showed that a low GNRI was an independent predictor for the discontinuation of lenvatinib, which led to a lower dose intensity and poor survival outcomes in patients with low GNRI.
The GNRI was proposed for predicting the risk of morbidity and mortality in hospitalized elderly patients by Bouillanne et al. in 2005 (9). Recently, a lower GNRI was reported to be associated with postoperative complications and poor survival outcomes in patients with lung cancer (16), colorectal cancer (17), gastric cancer (18), esophageal cancer (18), prostate cancer (19), diffuse large B-cell lymphoma (20), and $\mathrm{HCC}(10,11)$.

Body weight, one of the components of GNRI, is reported to be associated with tolerability of lenvatinib. The phase II study of lenvatinib in patients with advanced HCC showed that the median body weight $(54.1 \mathrm{~kg})$ was lower in patients with an early dose withdrawal or reduction than in those without it $(67.6 \mathrm{~kg})(21)$. A previous dose-finding study for lenvatinib in patients with HCC indicated that a greater lenvatinib area under the plasma concentration curve and lower body weight resulted in earlier drug withdrawal or dose reduction (22).

In addition to their lower body mass index and body weight, the factors of sarcopenia and frailty, which are likely to be common among low GNRI patients, may have affected the discontinuation of lenvatinib, although we were unable to evaluate sarcopenia or frailty in this study. Endo et al. showed that the time to discontinuation of lenvatinib due to AEs for HCC patients with a decreased grip strength was significantly shorter than that for patients with a normal grip strength (23). Uojima et al. also reported that HCC patients with a low skeletal muscle mass on CT had a significantly higher withdrawal rate of lenvatinib due to AEs than those with a high skeletal muscle mass (24). Cullinan et al. also reported that patients with frailty were twice as likely to experience at least one adverse drug reaction as those without frailty (25). As mentioned above, several researchers have shown the usefulness of sarcopenia or frailty for predicting the tolerability of cancer treatment. However, the measurement of sarcopenia or frailty in daily clinical practice is complex. Regarding sarcopenia, measuring the grip strength, gait speed, and area of the iliopsoas muscle at the third lumbar vertebra level on CT can be challenging in institutes that lack suitable equipment (11). Regarding frailty, there are many assessment tools for frailty or comprehensive geriatric assessments, such as Frailty phenotype, Frailty Index, Geriatric 8 frailty questionnaire for oncology (26), which are also challenging to implement in daily clinical practice. In contrast, Shoji showed that preoperative sarcopenia measured by CT was significantly related to the GNRI in patients with non-small cell lung cancer (27). Furthermore, Cereda showed that the GNRI was significantly associated with mid-upper arm muscle circumference and grip strength in institutionalized elderly patients (28).

Serum albumin, one of the components of the GNRI, reflects the nutritional status related to aging or comorbidities, inflammatory cytokines induced by cancer progression, and 
Table IV. Results of a multivariate analysis for factors associated with PFS.

\begin{tabular}{|c|c|c|c|c|c|}
\hline \multirow[b]{2}{*}{ Factors } & \multirow{2}{*}{$\frac{\text { Univariate }}{p \text {-Value }}$} & \multicolumn{2}{|c|}{ Multivariate Model 1} & \multicolumn{2}{|c|}{ Multivariate Model 2} \\
\hline & & Hazard ratio $(95 \% \mathrm{CI})$ & $p$-Value & Hazard ratio $(95 \% \mathrm{CI})$ & $p$-Value \\
\hline Age group ( $\geq 73$ years old) & 0.14 & - & & - & \\
\hline Gender (female) & 0.14 & - & & - & \\
\hline Creatinine $(\geq 0.84 \mathrm{mg} / \mathrm{dl})$ & 0.40 & - & & - & \\
\hline mALBI grade $(2 \mathrm{a} / 2 \mathrm{~b} / 3)$ & 0.042 & - & & - & \\
\hline BCLC stage (C) & 0.39 & - & & - & \\
\hline Portal vein invasion (yes) & 0.22 & - & & - & \\
\hline Extrahepatic spread (yes) & 0.90 & - & & - & \\
\hline $\operatorname{AFP}(\geq 9.2 \mathrm{ng} / \mathrm{ml})$ & 0.11 & - & & - & \\
\hline Objective response (PR/CR) & 0.063 & - & & $0.39(0.17-0.88)$ & 0.023 \\
\hline GNRI $(\leq 98)$ & 0.052 & - & & - & \\
\hline Initial dose of lenvatinib (12 mg) & 0.40 & - & & - & \\
\hline $8 \mathrm{w}-\mathrm{RDI}(\geq 67 \%)$ & 0.074 & - & & - & \\
\hline
\end{tabular}

PFS: Progression-free survival; CI: confidence interval; mALBI grade: modified albumin-bilirubin grade; BCLC stage: Barcelona Clinical Liver Cancer stage; AFP: $\alpha$-fetoprotein; CR: complete response; PR: partial response; GNRI: Geriatric Nutritional Risk Index; RDI: relative dose intensity. Significant $p$-Values are shown in bold.

liver functional reserve, which affects the tolerability of cancer treatment. Indeed, patients with hypoalbuminemia developed chemotherapy-induced toxicity (29) and showed early termination of chemotherapy more frequently than others (30).

Previous studies have found several factors associated with tolerability of lenvatinib. Shimose et al. demonstrated that age $\geq 71$ years old and ALBI grade 2 were independently associated with the discontinuation of lenvatinib due to AEs in patients with HCC treated with lenvatinib (7). Sasaki et al. showed that the time to reduction or discontinuation of lenvatinib was significantly shorter in the elderly group $(\geq 72$ years old) than in the younger group ( $<72$ years old) (8). Taken together, these findings suggest that age and liver functional reserve represented by the ALBI grade might affect the tolerability of lenvatinib in patients with HCC. The ROC analysis showed that the AUC values of the GNRI were higher than those of the age in the current study, implying that the GNRI is more strongly predictive of the tolerability of lenvatinib than the age.

The RDI at 8 weeks was significantly lower in the low GNRI group $(56.7 \%)$ than in the high GNRI group $(75 \%)$ in our study. Several studies have reported that the dose intensity of lenvatinib influenced the response to lenvatinib or the survival outcome. Takahashi et al. showed that patients with an RDI $\geq 75 \%$ at 8 weeks experienced a higher response rate and longer PFS than those with an RDI $<75 \%$ (31). Kirino et al. also showed that patients with an RDI $\geq 70 \%$ at 4 weeks had a higher disease control rate, longer duration of lenvatinib therapy, and longer overall survival than those with an RDI $<70 \%$ (32). In our study, the lower RDI at 8 weeks in the low GNRI group may have led to the lower DCR and shorter PFS compared to those in the high GNRI group.

The results of the current study suggest that the GNRI may be a useful and readily available tool for predicting the tolerability of lenvatinib in patients with HCC. Kanehira et al. reported that a low pretreatment GNRI $(<92)$ independently predicted the early discontinuation of azacitidine and poor survival outcomes in patients with myelodysplastic syndrome (33). These results are consistent with our results. Predicting the tolerability of cancer treatment before treatment is crucial for better treatment outcomes and should be simple and easy to use in daily clinical practice. In this respect, the GNRI can be useful and serve even as a simple method without additional imaging techniques or measuring equipment.

The current study has several limitations. First, this was a retrospective study with a small sample size. Second, we were unable to match both groups using propensity score matching due to the small sample size. Third, we were unable to obtain sufficient data, including the prevalence of sarcopenia, frailty, and nutritional assessment because of the multicenter, retrospective observational nature of the study. These methodological drawbacks might have affected the results of our study. A large-scale prospective study is warranted to confirm the findings of the current study.

\section{Conclusion}

We demonstrated that the GNRI is independently associated with the tolerability of lenvatinib in patients with HCC and can serve as a simple method without additional imaging techniques or measuring equipment in clinical practice. 


\section{Conflicts of Interest}

The Authors have no conflicts of interest to declare in relation to this study.

\section{Authors' Contributions}

Akiyoshi Kinoshita contributed to the data acquisition, study design, concept, statistical analysis and drafted the manuscript. Noriko Hagiwara, Akiyuki Osawa, Takafumi Akasu, Yoshihiro Matsumoto, Kaoru Ueda, Chisato Saeki, Tsunekazu Oikawa, Kazuhiko Koike contributed to data acquisition and edited the manuscript. Masayuki Saruta edited the manuscript.

\section{Acknowledgements}

The Authors thank the staff of Division of Gastroenterology and Hepatology, the Jikei University Daisan Hospital, the Jikei University Kashiwa Hospital, and Jikei University School of Medicine for their cooperation in this study.

\section{References}

1 Sangro B, Sarobe P, Hervás-Stubbs S and Melero I: Advances in immunotherapy for hepatocellular carcinoma. Nat Rev Gastroenterol Hepatol 18(8): 525-543, 2021. PMID: 33850328. DOI: $10.1038 / \mathrm{s} 41575-021-00438-0$

2 Global Burden of Disease Cancer Collaboration, Fitzmaurice C, Abate D, Abbasi N, Abbastabar H, Abd-Allah F, Abdel-Rahman O, Abdelalim A, Abdoli A, Abdollahpour I, Abdulle ASM, Abebe ND, Abraha HN, Abu-Raddad LJ, Abualhasan A, Adedeji IA, Advani SM, Afarideh M, Afshari M, Aghaali M, Agius D, Agrawal S, Ahmadi A, Ahmadian E, Ahmadpour E, Ahmed MB, Akbari ME, Akinyemiju T, Al-Aly Z, AlAbdulKader AM, Alahdab F, Alam T, Alamene GM, Alemnew BTT, Alene KA, Alinia C, Alipour V, Aljunid SM, Bakeshei FA, Almadi MAH, Almasi-Hashiani A, Alsharif U, Alsowaidi S, Alvis-Guzman N, Amini E, Amini S, Amoako YA, Anbari Z, Anber NH, Andrei CL, Anjomshoa M, Ansari F, Ansariadi A, Appiah SCY, ArabZozani M, Arabloo J, Arefi Z, Aremu O, Areri HA, Artaman A, Asayesh H, Asfaw ET, Ashagre AF, Assadi R, Ataeinia B, Atalay HT, Ataro Z, Atique S, Ausloos M, Avila-Burgos L, Avokpaho EFGA, Awasthi A, Awoke N, Ayala Quintanilla BP, Ayanore MA, Ayele HT, Babaee E, Bacha U, Badawi A, Bagherzadeh M, Bagli E, Balakrishnan S, Balouchi A, Bärnighausen TW, Battista RJ, Behzadifar M, Behzadifar M, Bekele BB, Belay YB, Belayneh YM, Berfield KKS, Berhane A, Bernabe E, Beuran M, Bhakta N, Bhattacharyya K, Biadgo B, Bijani A, Bin Sayeed MS, Birungi C, Bisignano C, Bitew H, Bjørge T, Bleyer A, Bogale KA, Bojia HA, Borzì AM, Bosetti C, Bou-Orm IR, Brenner H, Brewer JD, Briko AN, Briko NI, BustamanteTeixeira MT, Butt ZA, Carreras G, Carrero JJ, Carvalho F, Castro C, Castro F, Catalá-López F, Cerin E, Chaiah Y, Chanie WF, Chattu VK, Chaturvedi P, Chauhan NS, Chehrazi M, Chiang PP, Chichiabellu TY, Chido-Amajuoyi OG, ChimedOchir O, Choi JJ, Christopher DJ, Chu DT, Constantin MM, Costa VM, Crocetti E, Crowe CS, Curado MP, Dahlawi SMA, Damiani G, Darwish AH, Daryani A, das Neves J, Demeke FM, Demis AB, Demissie BW, Demoz GT, Denova-Gutiérrez E,
Derakhshani A, Deribe KS, Desai R, Desalegn BB, Desta M, Dey S, Dharmaratne SD, Dhimal M, Diaz D, Dinberu MTT, Djalalinia S, Doku DT, Drake TM, Dubey M, Dubljanin E, Duken EE, Ebrahimi H, Effiong A, Eftekhari A, El Sayed I, Zaki MES, El-Jaafary SI, El-Khatib Z, Elemineh DA, Elkout H, Ellenbogen RG, Elsharkawy A, Emamian MH, Endalew DA, Endries AY, Eshrati B, Fadhil I, Fallah Omrani V, Faramarzi M, Farhangi MA, Farioli A, Farzadfar F, Fentahun N, Fernandes E, Feyissa GT, Filip I, Fischer F, Fisher JL, Force LM, Foroutan M, Freitas M, Fukumoto T, Futran ND, Gallus S, Gankpe FG, Gayesa RT, Gebrehiwot TT, Gebremeskel GG, Gedefaw GA, Gelaw BK, Geta B, Getachew S, Gezae KE, Ghafourifard M, Ghajar A, Ghashghaee A, Gholamian A, Gill PS, Ginindza TTG, Girmay A, Gizaw M, Gomez RS, Gopalani SV, Gorini G, Goulart BNG, Grada A, Ribeiro Guerra M, Guimaraes ALS, Gupta PC, Gupta R, Hadkhale K, Haj-Mirzaian A, Haj-Mirzaian A, Hamadeh RR, Hamidi S, Hanfore LK, Haro JM, Hasankhani M, Hasanzadeh A, Hassen HY, Hay RJ, Hay SI, Henok A, Henry NJ, Herteliu C, Hidru HD, Hoang CL, Hole MK, Hoogar P, Horita N, Hosgood HD, Hosseini M, Hosseinzadeh M, Hostiuc M, Hostiuc S, Househ M, Hussen MM, Ileanu B, Ilic MD, Innos $\mathrm{K}$, Irvani SSN, Iseh KR, Islam SMS, Islami F, Jafari Balalami $\mathrm{N}$, Jafarinia M, Jahangiry L, Jahani MA, Jahanmehr $\mathrm{N}$, Jakovljevic M, James SL, Javanbakht M, Jayaraman S, Jee SH, Jenabi E, Jha RP, Jonas JB, Jonnagaddala J, Joo T, Jungari SB, Jürisson M, Kabir A, Kamangar F, Karch A, Karimi N, Karimian A, Kasaeian A, Kasahun GG, Kassa B, Kassa TD, Kassaw MW, Kaul A, Keiyoro PN, Kelbore AG, Kerbo AA, Khader YS, Khalilarjmandi M, Khan EA, Khan G, Khang YH, Khatab K, Khater A, Khayamzadeh M, Khazaee-Pool M, Khazaei S, Khoja AT, Khosravi MH, Khubchandani J, Kianipour N, Kim D, Kim YJ, Kisa A, Kisa S, Kissimova-Skarbek K, Komaki H, Koyanagi A, Krohn KJ, Bicer BK, Kugbey N, Kumar V, Kuupiel D, La Vecchia C, Lad DP, Lake EA, Lakew AM, Lal DK, Lami FH, Lan Q, Lasrado S, Lauriola P, Lazarus JV, Leigh J, Leshargie CT, Liao Y, Limenih MA, Listl S, Lopez AD, Lopukhov PD, Lunevicius R, Madadin M, Magdeldin S, El Razek HMA, Majeed A, Maleki A, Malekzadeh R, Manafi A, Manafi N, Manamo WA, Mansourian M, Mansournia MA, Mantovani LG, Maroufizadeh S, Martini SMS, Mashamba-Thompson TP, Massenburg BB, Maswabi MT, Mathur MR, McAlinden C, McKee M, Meheretu HAA, Mehrotra R, Mehta V, Meier T, Melaku YA, Meles GG, Meles HG, Melese A, Melku M, Memiah PTN, Mendoza W, Menezes RG, Merat S, Meretoja TJ, Mestrovic T, Miazgowski B, Miazgowski T, Mihretie KMM, Miller TR, Mills EJ, Mir SM, Mirzaei H, Mirzaei HR, Mishra R, Moazen B, Mohammad DK, Mohammad KA, Mohammad Y, Darwesh AM, Mohammadbeigi A, Mohammadi H, Mohammadi M, Mohammadian M, Mohammadian-Hafshejani A, Mohammadoo-Khorasani M, Mohammadpourhodki R, Mohammed AS, Mohammed JA, Mohammed S, Mohebi F, Mokdad AH, Monasta L, Moodley Y, Moosazadeh M, Moossavi M, Moradi G, Moradi-Joo M, Moradi-Lakeh M, Moradpour F, Morawska L, Morgado-da-Costa J, Morisaki N, Morrison SD, Mosapour A, Mousavi SM, Muche AA, Muhammed OSS, Musa J, Nabhan AF, Naderi M, Nagarajan AJ, Nagel G, Nahvijou A, Naik G, Najafi F, Naldi L, Nam HS, Nasiri N, Nazari J, Negoi I, Neupane S, Newcomb PA, Nggada HA, Ngunjiri JW, Nguyen CT, Nikniaz L, Ningrum DNA, Nirayo YL, Nixon MR, Nnaji CA, Nojomi M, Nosratnejad S, Shiadeh MN, Obsa MS, Ofori- 
Asenso R, Ogbo FA, Oh IH, Olagunju AT, Olagunju TO, Oluwasanu MM, Omonisi AE, Onwujekwe OE, Oommen AM, Oren E, Ortega-Altamirano DDV, Ota E, Otstavnov SS, Owolabi MO, P A M, Padubidri JR, Pakhale S, Pakpour AH, Pana A, Park EK, Parsian H, Pashaei T, Patel S, Patil ST, Pennini A, Pereira DM, Piccinelli C, Pillay JD, Pirestani M, Pishgar F, Postma MJ, Pourjafar H, Pourmalek F, Pourshams A, Prakash S, Prasad N, Qorbani M, Rabiee M, Rabiee N, Radfar A, Rafiei A, Rahim F, Rahimi M, Rahman MA, Rajati F, Rana SM, Raoofi S, Rath GK, Rawaf DL, Rawaf S, Reiner RC, Renzaho AMN, Rezaei N, Rezapour A, Ribeiro AI, Ribeiro D, Ronfani L, Roro EM, Roshandel G, Rostami A, Saad RS, Sabbagh P, Sabour S, Saddik B, Safiri S, Sahebkar A, Salahshoor MR, Salehi F, Salem H, Salem MR, Salimzadeh H, Salomon JA, Samy AM, Sanabria J, Santric Milicevic MM, Sartorius B, Sarveazad A, Sathian B, Satpathy M, Savic M, Sawhney M, Sayyah M, Schneider IJC, Schöttker B, Sekerija M, Sepanlou SG, Sepehrimanesh M, Seyedmousavi S, Shaahmadi F, Shabaninejad H, Shahbaz M, Shaikh MA, Shamshirian A, Shamsizadeh M, Sharafi H, Sharafi Z, Sharif M, Sharifi A, Sharifi H, Sharma R, Sheikh A, Shirkoohi R, Shukla SR, Si S, Siabani S, Silva DAS, Silveira DGA, Singh A, Singh JA, Sisay S, Sitas F, Sobngwi E, Soofi M, Soriano JB, Stathopoulou V, Sufiyan MB, Tabarés-Seisdedos R, Tabuchi T, Takahashi K, Tamtaji OR, Tarawneh MR, Tassew SG, Taymoori P, Tehrani-Banihashemi A, Temsah MH, Temsah O, Tesfay BE, Tesfay FH, Teshale MY, Tessema GA, Thapa S, Tlaye KG, Topor-Madry R, Tovani-Palone MR, Traini E, Tran BX, Tran KB, Tsadik AG, Ullah I, Uthman OA, Vacante M, Vaezi M, Varona Pérez P, Veisani Y, Vidale S, Violante FS, Vlassov V, Vollset SE, Vos T, Vosoughi K, Vu GT, Vujcic IS, Wabinga H, Wachamo TM, Wagnew FS, Waheed Y, Weldegebreal F, Weldesamuel GT, Wijeratne T, Wondafrash DZ, Wonde TE, Wondmieneh AB, Workie HM, Yadav R, Yadegar A, Yadollahpour A, Yaseri M, Yazdi-Feyzabadi V, Yeshaneh A, Yimam MA, Yimer EM, Yisma E, Yonemoto N, Younis MZ, Yousefi B, Yousefifard M, Yu C, Zabeh E, Zadnik V, Moghadam TZ, Zaidi Z, Zamani M, Zandian H, Zangeneh A, Zaki L, Zendehdel K, Zenebe ZM, Zewale TA, Ziapour A, Zodpey S and Murray CJL: Global, regional, and national cancer incidence, mortality, years of life lost, years lived with disability, and disability-adjusted life-years for 29 cancer groups, 1990 to 2017 : a systematic analysis for the Global Burden of Disease study. JAMA Oncol 5(12): 1749-1768, 2019. PMID: 31560378. DOI: 10.1001/jamaoncol.2019.2996

3 Kudo M, Finn RS, Qin S, Han KH, Ikeda K, Piscaglia F, Baron A, Park JW, Han G, Jassem J, Blanc JF, Vogel A, Komov D, Evans TRJ, Lopez C, Dutcus C, Guo M, Saito K, Kraljevic S, Tamai T, Ren $\mathrm{M}$ and Cheng AL: Lenvatinib versus sorafenib in first-line treatment of patients with unresectable hepatocellular carcinoma: a randomised phase 3 non-inferiority trial. Lancet 391(10126): 1163-1173, 2018. PMID: 29433850. DOI: 10.1016/S0140-6736(18)30207-1

4 Singal AG, Nagar SP, Hitchens A, Davis KL and Iyer S: Realworld effectiveness of lenvatinib monotherapy among unresectable hepatocellular carcinoma patients in the USA. Future Oncol 17(21): 2759-2768, 2021. PMID: 33832339. DOI: 10.2217/fon-2021-0242

5 Tsuchiya K, Kurosaki M, Sakamoto A, Marusawa H, Kojima Y, Hasebe C, Arai H, Joko K, Kondo M, Tsuji K, Sohda T, Kimura H, Ogawa C, Uchida Y, Wada S, Kobashi H, Furuta K, Shigeno
M, Kusakabe A, Akahane T, Narita R, Yoshida H, Mitsuda A, Ide Y, Matsushita T, Izumi N and On Behalf Of Japanese Red Cross Liver Study Group: The real-world data in Japanese patients with unresectable hepatocellular carcinoma treated with lenvatinib from a nationwide multicenter study. Cancers (Basel) 13(11): 2608, 2021. PMID: 34073396. DOI: 10.3390/ cancers 13112608

6 Hiraoka A, Kumada T, Atsukawa M, Hirooka M, Tsuji K, Ishikawa T, Takaguchi K, Kariyama K, Itobayashi E, Tajiri K, Shimada N, Shibata H, Ochi H, Tada T, Toyoda H, Nouso K, Tsutsui A, Nagano T, Itokawa N, Hayama K, Imai M, Joko K, Koizumi Y, Hiasa Y, Michitaka K, Kudo M and Real-life Practice Experts for HCC (RELPEC) Study Group, HCC 48 Group (hepatocellular carcinoma experts from 48 clinics in Japan): Prognostic factor of lenvatinib for unresectable hepatocellular carcinoma in real-world conditions-Multicenter analysis. Cancer Med 8(8): 3719-3728, 2019. PMID: 31127698. DOI: $10.1002 / \mathrm{cam} 4.2241$

7 Shimose S, Iwamoto H, Niizeki T, Shirono T, Noda Y, Kamachi N, Okamura S, Nakano M, Suga H, Kuromatsu R, Yamaguchi T, Kawaguchi T, Tanaka M, Noguchi K, Koga H and Torimura T: Clinical significance of adverse events for patients with unresectable hepatocellular carcinoma treated with lenvatinib: a multicenter retrospective study. Cancers (Basel) 12(7): 1867, 2020. PMID: 32664489. DOI: 10.3390/cancers 12071867

8 Sasaki R, Fukushima M, Haraguchi M, Miuma S, Miyaaki H, Hidaka M, Eguchi S, Matsuo S, Matsuzaki T, Hashimoto S, Ohba K, Kugiyama Y, Yatsuhashi H, Shibata H, Motoyoshi Y, Shigeno M, Iwatsu S, Kato Y, Kinoshita N and Nakao K: Liver function in older patients with unresectable hepatocellular carcinoma after administration of lenvatinib. Anticancer Res 41(4): 2025-2032, 2021. PMID: 33813409. DOI: 10.21873/ anticanres. 14970

9 Bouillanne O, Morineau G, Dupont C, Coulombel I, Vincent JP, Nicolis I, Benazeth S, Cynober L and Aussel C: Geriatric Nutritional Risk Index: a new index for evaluating at-risk elderly medical patients. Am J Clin Nutr 82(4): 777-783, 2005. PMID: 16210706. DOI: $10.1093 / \mathrm{ajcn} / 82.4 .777$

10 Li L, Wang H, Yang J, Jiang L, Yang J, Wu H, Wen T and Yan L: Geriatric nutritional risk index predicts prognosis after hepatectomy in elderly patients with hepatitis B virus-related hepatocellular carcinoma. Sci Rep 8(1): 12561, 2018. PMID: 30135506. DOI: 10.1038/s41598-018-30906-8

11 Kanno H, Goto Y, Sasaki S, Fukutomi S, Hisaka T, Fujita F, Akagi Y and Okuda K: Geriatric nutritional risk index predicts prognosis in hepatocellular carcinoma after hepatectomy: a propensity score matching analysis. Sci Rep 11(1): 9038, 2021. PMID: 33907232. DOI: 10.1038/s41598-021-88254-Z

12 European Association for the Study of the Liver and European Association for the Study of the Liver: EASL Clinical Practice Guidelines: Management of hepatocellular carcinoma. J Hepatol 69(1): 182-236, 2018. PMID: 29628281. DOI: 10.1016/j.jhep. 2018.03.019

13 Pugh RN, Murray-Lyon IM, Dawson JL, Pietroni MC and Williams R: Transection of the oesophagus for bleeding oesophageal varices. Br J Surg 60(8): 646-649, 1973. PMID: 4541913. DOI: $10.1002 / b j s .1800600817$

14 Hiraoka A, Michitaka K, Kumada T, Izumi N, Kadoya M, Kokudo N, Kubo S, Matsuyama Y, Nakashima O, Sakamoto M, Takayama T, Kokudo T, Kashiwabara K and Kudo M: Validation and 
potential of albumin-bilirubin grade and prognostication in a nationwide survey of 46,681 hepatocellular carcinoma patients in Japan: The need for a more detailed evaluation of hepatic function. Liver Cancer 6(4): 325-336, 2017. PMID: 29234636. DOI: $10.1159 / 000479984$

15 Lencioni R and Llovet JM: Modified RECIST (mRECIST) assessment for hepatocellular carcinoma. Semin Liver Dis 30(1): 52-60, 2010. PMID: 20175033. DOI: 10.1055/s-0030-1247132

16 Sonehara K, Tateishi K, Araki T, Komatsu M, Yamamoto H and Hanaoka M: Prognostic value of the geriatric nutritional risk index among patients with previously treated advanced nonsmall cell lung cancer who subsequently underwent immunotherapy. Thorac Cancer 12(9): 1366-1372, 2021. PMID: 33710780. DOI: 10.1111/1759-7714.13909

17 Sasaki M, Miyoshi N, Fujino S, Ogino T, Takahashi H, Uemura M, Matsuda C, Yamamoto H, Mizushima T, Mori M and Doki Y: The Geriatric Nutritional Risk Index predicts postoperative complications and prognosis in elderly patients with colorectal cancer after curative surgery. Sci Rep 10(1): 10744, 2020. PMID: 32612136. DOI: 10.1038/s41598-020-67285-y

18 Xie H, Tang S, Wei L and Gan J: Geriatric nutritional risk index as a predictor of complications and long-term outcomes in patients with gastrointestinal malignancy: a systematic review and meta-analysis. Cancer Cell Int 20(1): 530, 2020. PMID: 33292289. DOI: 10.1186/s12935-020-01628-7

19 Chang LW, Hung SC, Li JR, Chiu KY, Yang CK, Chen CS, Lu $\mathrm{K}$, Chen CC, Wang SC, Lin CY, Cheng CL, Ou YC, Yang SF, Hsu CY, Ho SH and Wang SS: Geriatric Nutritional Risk Index as a prognostic marker for patients with metastatic castrationresistant prostate cancer receiving docetaxel. Front Pharmacol 11: 601513, 2021. PMID: 33569000. DOI: 10.3389/fphar. 2020.601513

20 Go SI, Kim HG, Kang MH, Park S and Lee GW: Prognostic model based on the geriatric nutritional risk index and sarcopenia in patients with diffuse large B-cell lymphoma. BMC Cancer 20(1): 439, 2020. PMID: 32423395. DOI: 10.1186/ s12885-020-06921-2

21 Ikeda K, Kudo M, Kawazoe S, Osaki Y, Ikeda M, Okusaka T, Tamai T, Suzuki T, Hisai T, Hayato S, Okita K and Kumada H: Phase 2 study of lenvatinib in patients with advanced hepatocellular carcinoma. J Gastroenterol 52(4): 512-519, 2017. PMID: 27704266. DOI: 10.1007/s00535-016-1263-4

22 Tamai T, Hayato S, Hojo S, Suzuki T, Okusaka T, Ikeda K and Kumada H: Dose finding of lenvatinib in subjects with advanced hepatocellular carcinoma based on population pharmacokinetic and exposure-response analyses. J Clin Pharmacol 57(9): 11381147, 2017. PMID: 28561918. DOI: 10.1002/jcph.917

23 Endo K, Kuroda H, Kanazawa J, Sato T, Fujiwara Y, Abe T, Sato H, Kooka Y, Oikawa T, Sawara K and Takikawa Y: Impact of grip strength in patients with unresectable hepatocellular carcinoma treated with lenvatinib. Cancers (Basel) 12(8): 2146, 2020. PMID: 32756366. DOI: 10.3390/cancers 12082146

24 Uojima H, Chuma M, Tanaka Y, Hidaka H, Nakazawa T, Iwabuchi S, Kobayashi S, Hattori N, Ogushi K, Morimoto M, Kagawa T, Tanaka K, Kako M and Koizumi W: Skeletal muscle mass influences tolerability and prognosis in hepatocellular carcinoma patients treated with lenvatinib. Liver Cancer 9(2): 193-206, 2020. PMID: 32399433. DOI: 10.1159/000504604

25 Cullinan S, O'Mahony D, O'Sullivan D and Byrne S: Use of a frailty index to identify potentially inappropriate prescribing and adverse drug reaction risks in older patients. Age Ageing 45(1): 115-120, 2016. PMID: 26683048. DOI: 10.1093/ageing/afv166

26 Dent E, Martin FC, Bergman H, Woo J, Romero-Ortuno R and Walston JD: Management of frailty: opportunities, challenges, and future directions. Lancet 394(10206): 1376-1386, 2019. PMID: 31609229. DOI: 10.1016/S0140-6736(19)31785-4

27 Shoji F, Matsubara T, Kozuma Y, Haratake N, Akamine T, Takamori S, Katsura M, Toyokawa G, Okamoto T and Maehara Y: Relationship between preoperative sarcopenia status and immuno-nutritional parameters in patients with early-stage nonsmall cell lung cancer. Anticancer Res 37(12): 6997-7003, 2017. PMID: 29187486. DOI: 10.21873/anticanres.12168

28 Cereda E and Vanotti A: The new Geriatric Nutritional Risk Index is a good predictor of muscle dysfunction in institutionalized older patients. Clin Nutr 26(1): 78-83, 2007. PMID: 17067726. DOI: 10.1016/j.clnu.2006.09.007

29 Arrieta O, Michel Ortega RM, Villanueva-Rodríguez G, SernaThomé MG, Flores-Estrada D, Diaz-Romero C, Rodríguez CM, Martínez L and Sánchez-Lara K: Association of nutritional status and serum albumin levels with development of toxicity in patients with advanced non-small cell lung cancer treated with paclitaxel-cisplatin chemotherapy: a prospective study. BMC Cancer 10: 50, 2010. PMID: 20170547. DOI: 10.1186/14712407-10-50

30 Ikeda S, Yoshioka H, Ikeo S, Morita M, Sone N, Niwa T, Nishiyama A, Yokoyama T, Sekine A, Ogura T and Ishida T: Serum albumin level as a potential marker for deciding chemotherapy or best supportive care in elderly, advanced nonsmall cell lung cancer patients with poor performance status. BMC Cancer 17(1): 797, 2017. PMID: 29183294. DOI: 10.1186/s12885-017-3814-3

31 Takahashi A, Moriguchi M, Seko Y, Ishikawa H, Yo T, Kimura H, Fujii H, Shima T, Mitsumoto Y, Ishiba H, Takashima H, Nagao Y, Jo M, Arai M, Hara T, Okajima A, Muramatsu A, Morita A, Yoshinami N, Nakajima T, Mitsuyoshi H, Umemura A, Nishikawa T, Yamaguchi K and Itoh Y: Impact of relative dose intensity of early-phase lenvatinib treatment on therapeutic response in hepatocellular carcinoma. Anticancer Res 39(9): 5149-5156, 2019. PMID: 31519627. DOI: 10.21873/anticanres. 13710

32 Kirino S, Tsuchiya K, Kurosaki M, Kaneko S, Inada K, Yamashita K, Osawa L, Hayakawa Y, Sekiguchi S, Okada M, Wang W, Higuchi M, Takaura K, Maeyashiki C, Tamaki N, Yasui Y, Nakanishi H, Itakura J, Takahashi Y, Asahina Y and Izumi N: Relative dose intensity over the first four weeks of lenvatinib therapy is a factor of favorable response and overall survival in patients with unresectable hepatocellular carcinoma. PLoS One 15(4): e0231828, 2020. PMID: 32310967. DOI: 10.1371/journal.pone.0231828

33 Kanehira D, Koinuma M, Kato T, Abe T, Sagara A, Sato F and Yumoto T: Relationship between low pretreatment geriatric nutritional risk index and poor tolerability of azacitidine in patients with myelodysplastic syndromes. Ann Nutr Metab 76(6): 405-412, 2020. PMID: 33662960. DOI: 10.1159/ 000513542

Received November 7, 2021

Revised December 5, 2021

Accepted December 9, 2021 